University of Nebraska - Lincoln

DigitalCommons@University of Nebraska - Lincoln

Public Health Resources

Public Health Resources

2009

\title{
Children's Exposure to Violence: A Comprehensive National Survey
}

\author{
David Finkelhor \\ University of New Hampshire \\ Heather Turner \\ University of New Hampshire, Heather.Turner@unh.edu \\ Richard Ormrod \\ University of New Hampshire \\ Sherry Hamby \\ University of the South \\ Kristen Kracke \\ Office of Juvenile Justice and Delinquency Prevention
}

Follow this and additional works at: https://digitalcommons.unl.edu/publichealthresources

Part of the Public Health Commons

Finkelhor, David; Turner, Heather; Ormrod, Richard; Hamby, Sherry; and Kracke, Kristen, "Children's Exposure to Violence: A Comprehensive National Survey" (2009). Public Health Resources. 104. https://digitalcommons.unl.edu/publichealthresources/104

This Article is brought to you for free and open access by the Public Health Resources at DigitalCommons@University of Nebraska - Lincoln. It has been accepted for inclusion in Public Health Resources by an authorized administrator of DigitalCommons@University of Nebraska - Lincoln. 


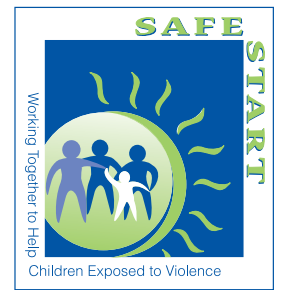

\section{David Finkelhor, Heather Turner, Richard Ormrod, Sherry Hamby, and Kristen Kracke}

This Bulletin discusses the National Survey of Children's Exposure to Violence (NatSCEV), the most comprehensive nationwide survey of the incidence and prevalence of children's exposure to violence to date, sponsored by the Office of Juvenile Justice and Delinquency Prevention (OJJDP) and supported by the Centers for Disease Control and Prevention (CDC). Conducted between January and May 2008, it measured the past-year and lifetime exposure to violence for children age 17 and younger across several major categories: conventional crime, child maltreatment, victimization by peers and siblings, sexual victimization, witnessing and indirect victimization (including exposure to community violence and family violence), school violence and threats, and Internet victimization. (For more detailed information on the types of violence that children were questioned about, see "Screening Questions" on page 2.) This survey is the first comprehensive attempt to measure children's exposure to violence in the home, school, and community across all age groups from birth to age 17, and the first attempt to measure the cumulative exposure to violence over the child's lifetime.

The survey confirms that most of our society's children are exposed to violence in their daily lives. More than 60 percent of the children surveyed were exposed to violence within the past year, either directly or indirectly (i.e., as a witness to a violent act; by learning of a violent act against a family member, neighbor, or close friend; or from a threat against their home or school) (for full details on these and other statistics cited in this Bulletin, see Finkelhor et al., 2009). Nearly one-half of the children and adolescents surveyed (46.3 percent) were assaulted at least once in the past year, and more than 1 in 10 (10.2 percent) were injured in an assault; 1 in 4 (24.6 percent) were victims of robbery, vandalism, or theft; 1 in 10 (10.2 percent) suffered from child maltreatment (including physical and emotional abuse, neglect, or a family abduction); and 1 in 16 (6.1 percent) were victimized sexually. More than 1 in 4 (25.3 percent) witnessed a violent act

\section{A Message From OJJDP}

Children are exposed to violence every day in their homes, schools, and communities. They may be struck by a boyfriend, bullied by a classmate, or abused by an adult. They may witness an assault on a parent or a shooting on the street. Such exposure can cause significant physical, mental, and emotional harm with long-term effects that can last well into adulthood.

In 1999, OJJDP created the Safe Start Initiative to prevent and reduce the impact of children's exposure to violence through enhanced practice, research, evaluation, training and technical assistance, resources, and outreach. The initiative has improved the delivery of developmentally appropriate services for children exposed to violence and their families.

Understanding the nature and extent of children's exposure to violence is essential to combating its effects. Partnering with the Centers for Disease Control and Prevention, OJJDP has sponsored the most comprehensive effort to date to measure children's exposure to violence. The National Survey of Children's Exposure to Violence is the first survey to ask children and caregivers about exposure to a range of violent incidents and maltreatment.

As amply evidenced in this Bulletin, children's exposure to violence is pervasive and crosses all ages. The research findings reported here are critical to informing our efforts to protect children from its damaging effects. 
and nearly 1 in 10 (9.8 percent) saw one family member assault another. Multiple victimizations were common: more than one-third (38.7 percent) experienced 2 or more direct victimizations in the previous year, more than 1 in 10 (10.9 percent) experienced 5 or more direct victimizations in the previous year, and more than 1 in 75 (1.4 percent) experienced 10 or more direct victimizations in the previous year.

Reports of lifetime exposure to violence were generally about one-third to one-half higher than reports of past-year exposure, although the difference tended to be greater for less frequent and more severe types of victimization. (For example, more than three times as many respondents reported being victims of a kidnapping over their lifetimes as did in the past year.) Nearly seven in eight children (86.6 percent) who reported being exposed to violence during their lifetimes also reported being exposed to violence within the past year, which indicated that these children were at ongoing risk of violent victimization. The reports of lifetime exposure also indicate how certain types of exposure change and accumulate as a child grows up; nearly one in five girls ages 14 to 17 (18.7 percent) had been the victim of a sexual assault or attempted sexual assault, and more than one-third of all 14- to 17-year-olds had seen a parent assaulted.

\section{Background}

\section{The Problem of Violence Against Children}

Children in the United States are more likely to be exposed to violence and crime than are adults (Finkelhor, 2008; Hashima and Finkelhor, 1999). In 2005, juveniles and young adults ages 12 to 19 were more than twice as likely to be victims of violent crimes as the population as a whole (Baum, 2005). ${ }^{1}$ Each year, millions of children and adolescents in the United States are exposed to violence in their homes, schools, and communities as both victims and witnesses. Even if they are not physically present, children may be affected by intentional harm done by another (for example, the murder of or an assault on a family member or close neighbor). Children react to exposure to violence in different ways, and many children show remarkable resilience. All too often,

\section{Screening Questions}

The survey asked screening questions about 48 types of victimization in the following categories:

- Conventional crime. Nine types of victimization, including robbery, theft, destruction of property, attack with an object or weapon, attack without an object or weapon, attempted attack, threatened attack, kidnapping or attempted kidnapping, and hate crime or bias attack (an attack on a child because of the child's or parent's skin color, religion, physical problem, or perceived sexual orientation).

- Child maltreatment. Four types of victimization, including being hit, kicked, or beaten by an adult (other than spanking on the bottom); psychological or emotional abuse; neglect; and abduction by a parent or caregiver, also known as custodial interference.

- Peer and sibling victimization. Six types of victimization, including being attacked by a group of children; being hit or beaten by another child, including a brother or sister; being hit or kicked in the private parts; being chased, grabbed, or forced to do something; being teased or emotionally bullied; and being a victim of dating violence.

$\checkmark$ Sexual victimization. Seven types of victimization, including sexual contact or fondling by an adult the child knew, sexual contact or fondling by an adult stranger, sexual contact or fondling by another child or teenager, attempted or completed intercourse, exposure or "flashing," sexual harassment, and consensual sexual conduct with an adult.

Witnessing and indirect victimization. These fall into two general categories, exposure to community violence and exposure to family violence. For exposure to community violence, the survey included 10 types of victimization, including seeing someone attacked with an object or weapon; seeing someone attacked without an object or weapon; having something stolen from the household; having a friend, neighbor, or family member murdered; witnessing a murder; witnessing or hearing a shooting, bombing, or riot; being in a war zone; knowing a family member or close friend who was fondled or forced to have sex; knowing a family member or close friend who was robbed or mugged; and knowing a family member or close friend who was threatened with a gun or knife.

For exposure to family violence, eight types of victimization were assessed: seeing a parent assaulted by a spouse, domestic partner, or boyfriend or girlfriend; seeing a brother or sister assaulted by a parent; threat by one parent to assault the other; threat by a parent to damage the other parent's property; one parent pushing the other; one parent hitting or slapping the other; one parent kicking, choking, or beating up the other; and assault by another adult household member against a child or adult in the household.

- School violence and threat. Two types of victimization, including a credible bomb threat against the child's school and fire or other property damage to the school.

- Internet violence and victimization. Two types of victimization, including Internet threats or harassment and unwanted online sexual solicitation.

however, children who are exposed to violence undergo lasting physical, mental, and emotional harm. They suffer from difficulties with attachment, regressive behavior, anxiety and depression, and aggression and conduct problems. They may be more prone to dating violence, delinquency, further victimization, and involvement with the child welfare and juvenile justice systems. Moreover, being exposed to violence may impair a child's capacity for partnering and parenting later in life, continuing the cycle of violence into the next generation.
Research has found that early identification, intervention, and continued followup are valuable strategies to prevent or decrease the impact of exposure to violence. Families, teachers, police, judges, pediatricians, mental health providers, child protection workers, domestic violence advocates, and others who interact with children have a responsibility to create interventions, both physical and psychological, that decrease or prevent the harms associated with exposure to violence. ${ }^{2}$ These include ways of interacting sensitively and expeditiously with 
children, ensuring protective environments and caregivers, and helping children use positive coping skills. Much more research is warranted about what works to mitigate the effects of exposure to violence.

Too little is known about the numbers of children exposed to violence. Although several studies have attempted to measure children's exposure to violence, these estimates have varied greatly and have often measured only a subset of that exposure. ${ }^{3}$ Not only does this partial measurement fail to reveal the full extent of violence against children, it also fails to account fully for the multiple victimizations that many children experience; the co-occurrence of certain types of violence (for example, intimate partner violence and child maltreatment or neglect within a household); the extent to which exposure to one type of violence may make a child more vulnerable to other types of violence and victimization; and the cumulative effects of repeated exposure to violence as both a direct victim and a witness. Basic epidemiological data are important to determine the extent of the public health problem, the need for services, and a baseline for evaluating progress.

\section{Prior Attempts at Comprehensive Measurements}

There have been many studies on the health and behavioral consequences of child maltreatment and, to a lesser extent, on other forms of violence against children. ${ }^{4}$ However, most of these studies focused on only one type of violence or on a few types within a single category such as child abuse. ${ }^{5}$ Two notable earlier studies attempted to measure children's exposure to violence and its adverse effects in a more comprehensive fashion. The Adverse Childhood Experiences (ACE) study, cosponsored by CDC and Kaiser Permanente, looked at the consequences for future health and well-being of exposure to seven types of adverse childhood experiences ${ }^{6}$ under the categories of abuse, neglect, and household dysfunction. Almost two-thirds of those surveyed had suffered at least one adverse childhood experience, and more than one in five respondents reported three or more such experiences. The survey found increased rates of a number of long-term harms to physical, mental, and emotional health associated with those experiences,

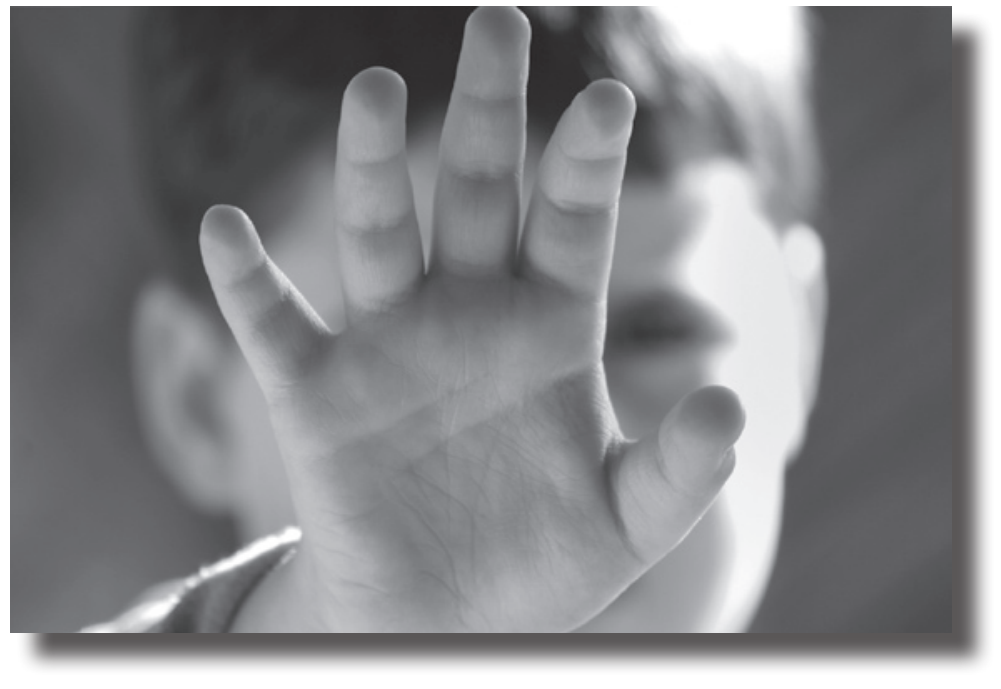

including alcoholism, drug abuse, depression, severe obesity, and several chronic adult diseases. The survey further found that multiple adverse experiences compounded those harms. Although the ACE study was one of the first to document the long-term consequences of multiple childhood victimizations, it had a different focus than NatSCEV. For one, the study questioned adults on their memories of adverse childhood experiences rather than surveying children directly, and the set of adverse experiences was more limited than those included in NatSCEV.

The other major attempt to examine the prevalence and incidence of children's exposure to violence was the Developmental Victimization Survey (DVS), a precursor to NatSCEV. DVS asked a nationally representative sample of 2,030 children ages 10 to 17 and caregivers of children ages 2 to 9 about their past-year exposure to crime and violence in five categories: conventional crime, child maltreatment, peer and sibling victimization, sexual assault, and witnessing and indirect victimization (Finkelhor et al., 2005; Kracke and Hahn, 2008). DVS was the first survey to simultaneously examine these various forms of victimization to obtain a comprehensive picture of children's exposure to violence. It was also the first national survey to estimate the incidence of many specific forms of victimization such as bias attacks and witnessing physical abuse (Finkelhor et al., 2005; Kracke and Hahn, 2008). DVS generally found a higher rate of specific types of victimization than earlier studies such as the National Crime Victimization Survey. Nearly three-quarters of the respondents (71 percent) reported a direct or indirect victimization within the past year, and the average young victim reported three separate types of victimizations in separate incidents. More than one-third of those surveyed reported that they witnessed violence or were otherwise indirect victims of violence. DVS, however, provided only a limited assessment of lifetime incidence of exposure to violence; did not look specifically at items such as threats and Internet victimization; and had limited measurement of exposure to family violence, exposure to community violence, and school violence and threats. DVS also did not include children younger than age 2. NatSCEV expands on DVS by comprehensively assessing lifetime exposure, considering additional forms of violence, and including infants in the sample. With its much larger sample size, NatSCEV also allows for much more reliable estimates of rarer forms of victimization and more accurate rates within different subgroups of the population (Finkelhor et al., 2009).

\section{History of the Current Study}

Under the leadership of then Deputy Attorney General Eric Holder in June 1999, OJJDP created the Safe Start Initiative to prevent and reduce the impact of children's exposure to violence. As a part of this initiative and with a growing need to document the full extent of children's exposure to violence, OJJDP launched the National Survey of Children's Exposure to Violence.

Safe Start's NatSCEV is the first national incidence and prevalence study to examine 


\section{Exhibit 1: Past-Year Exposure to Selected Categories of Violence for All Children Surveyed}

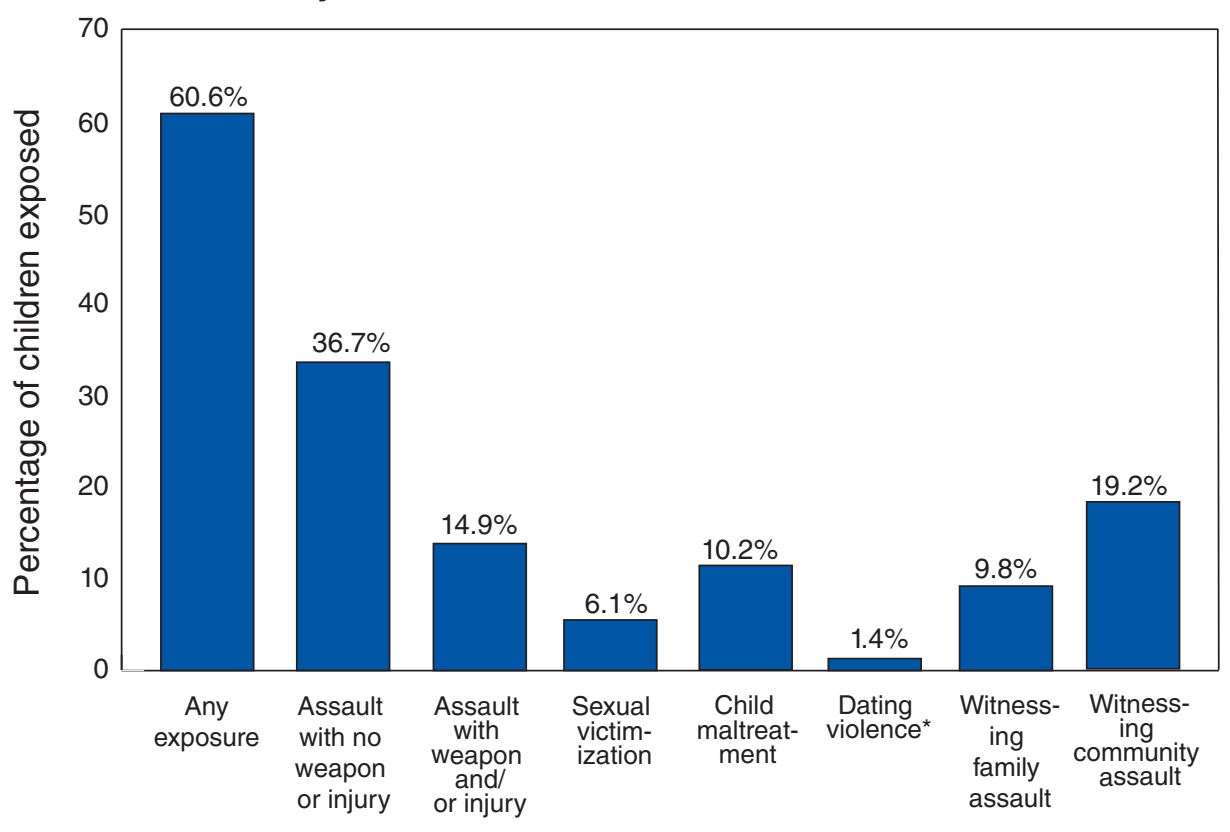

Type of violence

* Figures for dating violence are only for children and adolescents age 12 and older.

comprehensively the extent and nature of children's exposure to violence across all ages, settings, and timeframes (see "Methodology" on page 6). It measures their experience of violence in the home, school, and community. It asked children and their adult caregivers about not only the incidents of violence that children suffered and witnessed themselves but also other related crime and threat exposures, such as theft or burglary from a child's household, being in a school that was the target of a credible bomb threat, and being in a war zone or an area where ethnic violence occurred. It includes both the past-year and lifetime exposure to violence of children of all ages up to age 17. The study was developed under the direction of OJJDP, and was designed and conducted by the Crimes against Children Research Center of the University of New Hampshire. It provides comprehensive data on the full extent of violence in the daily lives of children. The primary purpose of NatSCEV is to document the incidence and prevalence of children's exposure to a broad array of violent experiences across a wide developmental spectrum. The research team asked followup questions about specific events, including where the exposure to violence occurred, whether injury resulted, how often the child was exposed to a specific type of violence, and the child's relationship to the perpetrator and (when the child witnessed violence) the victim. In addition, the study documents differences in exposure to violence across gender, race, socioeconomic status, family structure, region, urban/rural residence, and developmental stage of the child; specifies how different forms of violent victimization "cluster" or co-occur; identifies individual, family, and community-level predictors of violence exposure among children; examines associations between levels/types of violence exposure and child mental and emotional health; and assesses the extent to which children disclose incidents of violence to various individuals and the nature and source of assistance or treatment provided (if any).

This study began in 2007 with funding from OJJDP's Safe Start Initiative. OJJDP then partnered with CDC to collect additional data on safe, stable, and nurturing relationships - a key focus for CDC's child maltreatment prevention activities. The combined approach by OJJDP and CDC is providing critical national data on levels of violence as well as data on key indicators of protective factors.

\section{Highlights of the Survey Results}

NatSCEV estimates both past-year and lifetime exposure to violence across a number of categories, including physical assault, bullying, sexual victimization, child maltreatment, dating violence, and witnessed and indirect victimization (See "Methodology" on page 6 for more detailed definitions of these terms). Exhibit 1 illustrates the past-year exposure for all survey respondents to selected categories of violence. Some of the more notable findings are outlined below (see Finkelhor et al., 2009, for more details).

As noted earlier, the NatSCEV survey found that children's exposure to violence is common; more than 60 percent of the children surveyed had been exposed to violence in the past year and more than 1 in 10 reported 5 or more exposures. This exposure occurs across all age ranges of childhood and for both genders. In general, however, the types of exposure that were most prevalent among younger children were less serious, such as assaults without a weapon or without injury, assaults by a juvenile sibling, or bullying and teasing, all of which were most common among 6- to 9-year-olds and declined thereafter. Older adolescents ages 14 to 17 were the most likely to experience more serious forms of violence, including assaults with injury, gang assaults, sexual victimizations, and physical and emotional abuse, and to witness violence in the community. (See exhibit 2 for a list of the most common victimizations for each age range from infancy to later adolescence.) This is not a hard and fast distinction; some serious forms of victimization, including kidnapping and assaults with a weapon, were most common among 10- to 13-year-olds. This age group was also the most likely to witness violence within the home, including domestic violence involving their parents and assaults by other family members.

The following sections provide more details about the findings of the study regarding children's exposure to major categories of violence, including assaults, bullying, sexual victimization, child maltreatment, and witnessing and indirect victimization. The Bulletin then discusses the study's findings about multiple and cumulative exposures 


\section{Exhibit 2: Developmental Patterns in Exposure to Violence}

\section{Victimization in Infancy \\ Most common victimizations during this period:}

Assault by a sibling

Assault with no weapon or injury

Witnessing family assault

Victimization in the Toddler Years (Ages 2 to 5)

Most common victimizations during

this period:

Assault by a sibling

Assault with no weapon or injury

Bullying (physical)

Witnessing family assault

\section{Victimization in Middle Childhood} (Ages 6 to 9)

Peak risk period for:

Assault by a sibling

Assault with no weapon or injury

Bullying (physical)

Emotional bullying/teasing

\section{Victimization in Preteens and Early} Adolescence (Ages 10 to 13)

Peak risk period for:

Assault with weapon

Sexual harassment (same rate ages 10 to 17 )

Kidnapping

Witnessing family assault

Witnessing intimate partner (interparental) violence

\section{Victimization in Later Adolescence} (Ages 14 to 17)

Peak risk period for:

Assault with injury

Assault by peer (nonsibling)

Genital assault

Dating violence

Sexual victimizations of all types

Sexual assault

Sexual harassment (same rate ages 10 to 17)

Flashing or sexual exposure Unwanted online sexual solicitation Any maltreatment

Physical abuse

Psychological or emotional abuse

Witnessing community assault

Exposure to shooting

School threat of bomb or attack to violence, including documentation that children who are exposed to one form of violence are at greatly increased risk for being exposed to violence in other forms.

\section{Physical Assault}

Nearly one-half (46.3 percent) of all the children surveyed were physically assaulted within the previous year, and more than one-half (56.7 percent) had been assaulted during their lifetime. Physical assaults are extremely common across the entire span of childhood and peak during middle childhood. Assaults by siblings especially show a marked developmental trend, peaking during the middle childhood years (ages 6 to 9) and then declining. Incidence for the most severe assaults, however, rises steadily with age. Among 14- to 17-year-olds, nearly one in five (18.8 percent) had been injured in the past year in a physical assault. New forms of violence, such as dating violence, also emerge during adolescence, reaching a 5.6-percent past-year incidence rate and an 8.8-percent lifetime rate for the oldest adolescents. The lifetime incidence of assault victimization generally rose steadily as children grew older, with more than 7 in 1014 - to 17 -year-olds (71.1 percent) reporting that they had been assaulted during their lifetimes (Finkelhor et al., 2009).

In general, boys are somewhat more likely than girls to be victims of assault. The past-year incidence of assault is $\mathbf{5 0 . 2}$ percent for boys and 42.1 percent for girls, and the lifetime incidence of assault is 60.3 percent for boys and 52.9 percent for girls. These patterns are consistent with other data on criminal victimization, which typically show that males are the most common targets of physical assault (Finkelhor, 2008; Kilpatrick, Saunders, and Smith, 2003; Baum, 2005; Rand, 2008).

\section{Bullying}

The survey looked at bullying separately from assault and asked about multiple types of bullying: physical bullying, emotional bullying, and Internet harassment. Overall, 13.2 percent of those surveyed reported having been physically bullied within the past year, and more than one in five (21.6 percent) reported having been physically bullied during their lifetimes. The risk of bullying peaks during middle childhood in a pattern similar to that for sibling assault. The highest incidence occurs among 6- to 9-year-olds, who had rates of 21.5 percent past-year incidence and 28.0 percent lifetime incidence.

About 1 in 5 children (19.7 percent) reported having been teased or emotionally bullied in the previous year and nearly 3 in 10 reported having been teased or emotionally bullied in their lifetimes. Teasing or emotional bullying followed a similar pattern to physical bullying among age groups, rising to reach a peak among 6- to 9-year-olds, nearly one-third of whom (30.4 percent) reported having been teased in the past year and then falling steadily thereafter.

Internet harassment was less common than other forms of bullying. Questions about Internet harassment were asked only of youth age 10 and older, who might be most likely to independently use a computer. Unlike other forms of bullying, the peak risk period for Internet harassment was ages 14 to 17. In this group, 5.6 percent reported Internet harassment within the past year and 7.9 percent during their lifetimes.

Boys were more likely than girls to be physically bullied or threatened, but girls were more likely to be victims of Internet harassment. For past-year rates, there were no significant gender differences in emotional bullying; however, for lifetime rates, girls reported more cumulative exposure to emotional bullying than boys (Finkelhor et al., 2009).

\section{Sexual Victimization}

Overall, 6.1 percent of all children surveyed had been sexually victimized in the past year and nearly 1 in 10 (9.8 percent) over their lifetimes. Sexual victimizations included attempted and completed rape (1.1 percent past year, 2.4 percent lifetime); sexual assault by a known adult ( 0.3 percent past year, 1.2 percent lifetime), an adult stranger $(0.3$ percent past year, 0.5 percent lifetime), or a peer (1.3 percent past year, 2.7 percent lifetime); flashing or sexual exposure by an adult ( 0.4 percent past year, 0.6 percent lifetime) or peer (2.2 percent past year, 3.7 percent lifetime); sexual harassment (2.6 percent past year, 4.2 percent lifetime); and statutory sexual offenses ( 0.1 percent past year, 0.4 percent lifetime). ${ }^{7}$ Adolescents ages 14 to 17 were by far the most likely to be sexually victimized; nearly one in six (16.3 percent) was sexually victimized in the 
past year, and more than one in four (27.3 percent) had been sexually victimized during their lifetimes. The most common forms of sexual victimization were flashing or exposure by a peer, sexual harassment, and sexual assault.

Girls were more likely than boys to be sexually victimized: 7.4 percent of girls reported a sexual victimization within the past year, and nearly one in eight (12.2 percent) reported being sexually victimized during their lifetimes. Girls ages 14 to 17 had the highest rates of sexual victimization: 7.9 percent were victims of sexual assault in the past year and 18.7 percent during their lifetimes (Finkelhor et al., 2009).

\section{Child Maltreatment}

Overall, more than 1 in 10 children surveyed (10.2 percent) suffered some form of maltreatment (including physical abuse other than sexual assault, psychological or emotional abuse, child neglect, and custodial interference) during the past year and nearly 1 in 5 (18.6 percent) during their lifetimes. Both the past-year and lifetime rates of exposure to maltreatment rose as children grew older, particularly for children age 10 and older: one in six 14- to 17-year-olds (16.6 percent) suffered maltreatment during the past year and nearly one in three (32.1 percent) during their lifetimes.

Patterns of child maltreatment were similar for girls and boys with the exception of psychological or emotional abuse, the incidence of which was somewhat higher for girls than for boys. Rates of sexual assault by a known adult (not limited to caregivers) were also higher for girls than for boys, in a pattern that was similar to other forms of sexual victimization.

\section{Witnessing and Indirect Exposure to Violence}

NatSCEV found that witnessing violence was a common occurrence for children, particularly as they grew older. Overall, more than one-quarter of children surveyed (25.3 percent) had witnessed violence in their homes, schools, and communities during the past year; and more than one-third (37.8 percent) had witnessed violence against another person during their lifetimes. The proportion of children who witnessed violence both within the past year and during their lifetimes rose from one age group to the next.

\section{Methodology}

The National Survey of Children's Exposure to Violence (NatSCEV) was conducted between January and May 2008. Researchers conducted interviews about the experiences of a nationally representative sample of 4,549 children and adolescents age 17 and younger. They interviewed by telephone youth ages 10 to 17 and adult caregivers of children age 9 and younger. Because telephone interviews afford greater anonymity and privacy than in-person interviews, they may encourage those interviewed to be more forthcoming about such sensitive matters as being exposed to violence or being victims of crime.

The interview sample ( $n=4,549$ ) consisted of 2 groups: a nationally representative sample of telephone numbers within the contiguous United States $(n=3,053)$ and an oversample of telephone exchanges with 70 percent or greater African American, Hispanic, or low-income households to ensure a proportion of minority and low-income households large enough for subgroup analysis. Both groups were sampled through random-digit dialing. The cooperation rate for the first group was 71 percent and the response rate was 54 percent. The oversample had somewhat lower cooperation (63 percent) and response rates (43 percent). A nonresponse analysis conducted on households that could not be contacted or that declined to participate indicated that the risk of victimization for those households did not differ systematically from the risk for households that took part in the survey.

An adult, usually a parent, provided demographic information for each participating household, including race/ethnicity (one of four categories: white, nonHispanic; black, non-Hispanic; other race, non-Hispanic; and Hispanic, any race) and household income. The child in the household with the most recent birthday was then selected to be surveyed. Interviewers spoke directly with children age 10 and older; for children age 9 and younger, the parent or other adult caregiver "most familiar with the child's daily routine and experience" was interviewed. Comparison of a number of indicators, including reports of child maltreatment or neglect and violence by family members, found no evidence that caregivers who answered for younger children failed to report neglect or violence that was occurring in the family.

Interviews averaged about 45 minutes in length and were conducted in both English and Spanish. Approximately 279 caregiver interviews were conducted in Spanish; almost all interviews with children and adolescents 10 and older were in English.

\section{Types of Violent Victimization Surveyed}

Interviewers asked the children or their caregivers about their exposure to selected types of violence in the past year and over their lifetimes (see "Screening Questions" on page 2). In addition, interviewers asked followup questions about the perpetrator, the use of a weapon, injury, and whether multiple events
Of all forms of victimization measured in NatSCEV, witnessing community violence showed the strongest age trends. There was more than a sevenfold increase in rates from toddlers (2- to 5-year-olds) to older adolescents (14- to 17-year-olds). More than 7 in 10 14- to 17-year-olds had witnessed violence against another person during their lives.

These age trends were due mostly to witnessing violence in the community. The past-year incidence of witnessing assaults in the community rose from 5.8 percent among 2- to 5-year-olds to 42.2 percent among 14- to 17-year-olds; lifetime incidence rose even more dramatically, from 9.0 percent of 2- to 5-year-olds to nearly twothirds (64.2 percent) of 14 - to 17 -year-olds. Witnessing of shootings also rose sharply in both past-year and lifetime incidence from one age group to the next. Among children younger than 2 years old, 1.1 percent were exposed to shootings in the past year, whereas more than 1 in 10 14to 17 -year-olds (10.2 percent) witnessed a shooting in the past year. Similarly, 3.5 percent of 2- to 5-year-olds had witnessed a shooting during their lifetimes, whereas more than one in five 14- to 17-year-olds (22.2 percent) had witnessed a shooting. ${ }^{8}$ As striking as these age trends are, even 


\section{Methodology (continued)}

occurred together. Because different types of victimization can occur together and some events fall into more than one category (for example, physical abuse by a parent or caretaker can also be considered an assault), a number of items were rescored. A total of 51 victimization items were extracted in the following categories:

- Assaults. These included any physical assault, assault with a weapon, assault with injury, assault without a weapon, attempted assault, attempted or completed kidnapping, assault by a brother or sister, assault by another child or adolescent, nonsexual genital assault, dating violence, bias attacks, and threats.

- Bullying. This included physical bullying, teasing or emotional bullying, and Internet harassment.

- Sexual victimization. This included completed or attempted rape; sexual assault by an adult acquaintance, an adult stranger, or another child or adolescent; flashing by an adult or another child or adolescent; sexual harassment orally or in writing; statutory sexual offenses; and unwanted online sexual solicitation.

- Child maltreatment by an adult. This included physical abuse, psychological or emotional abuse, neglect, and custodial interference or family abduction.

- Witnessed and indirect victimization. Witnessed victimization included witnessing the following: an assault by one parent or family member against another, an assault by a parent on a brother or sister, an assault on a family member by someone outside the household, an assault outside the home, or a murder. Types of indirect victimization included exposure to shooting, bombs, or riots; exposure to war or ethnic conflict; being told about or seeing evidence of a violent event in the child's household or community; theft or burglary from the child's household; or a credible threat of a bomb or attack against the child's school.

\section{Limitations}

The survey methodology has several limitations that may cause it to understate children's actual exposure to violence. First, because the survey required the cooperation of the family, it ran the risk of missing those children who were most vulnerable to being exposed either to violence in general or to specific types of violence. Second, parents or caregivers who answer for younger children may not know about all of a child's exposure to violence or may underreport or minimize certain types of victimization. Third, the screening and followup questions may miss some episodes of victimization and incorrectly classify others. Fourth, children may not recall some exposure to violence, particularly less serious exposure, or may not accurately recall the timing of their exposure (i.e., whether or not the exposure occurred within the past year). Despite these limitations, NatSCEV provides the most detailed and comprehensive data available on youth victimization.

the lower numbers among young children are cause for great concern.

In contrast to the patterns for witnessing community violence, few age trends in exposure can be seen for witnessing violence within the family. Rates for witnessing family violence were fairly constant across the span of childhood, with all age groups falling in a fairly narrow range of approximately 6 to 11 percent.

Over the course of their lifetimes, boys overall were slightly more likely than girls to witness violence (40.1 percent of boys and 35.4 percent of girls). Boys were more likely to witness violence in the community, murder, and shootings both in the past year and during their lifetimes. There were no gender differences in witnessing family violence (Finkelhor et al., 2009).

\section{Multiple and Cumulative Victimizations}

A large proportion of children surveyed (38.7 percent) reported more than one direct victimization (a victimization directed toward the child, as opposed to an incident that the child witnessed, heard, or was otherwise exposed to) within the previous year. Of those who reported any direct victimization, nearly two-thirds (64.5 percent) reported more than one. A significant number of children reported high levels of exposure to violence in the past year: more than 1 in 10 (10.9 percent) reported 5 or more direct exposures to violence, and 1.4 percent reported 10 or more direct victimizations. (Victimizations that could be counted in more than one category, such as physical abuse by a parent or caregiver that could also be considered an assault, were not included in the counting of multiple victimizations. See "Methodology" for a discussion of this point.)

Children who were exposed to one type of violence, both within the past year and over their lifetimes, were at far greater risk of experiencing other types of violence. For example, a child who was physically assaulted in the past year would be five times as likely to also have been sexually victimized and more than four times as likely also to have been maltreated during that period. Similarly, a child who was physically assaulted during his or her lifetime would be more than six times as likely to have been sexually victimized and more than five times as likely to have been maltreated during his or her lifetime.

\section{Implications for Policymakers, Researchers, and Practitioners}

The findings of the NatSCEV study confirm that for many children in the United States, violence is a frequent occurrence. Of the nationally representative sample of U.S. youth who participated in the study, more than 60 percent reported that they were victims of direct or indirect violence in the past year. Furthermore, nearly twothirds of those participants were victimized more than once. Nearly one-half of the children surveyed reported that they were assaulted during the previous year, and more than 10 percent of them were injured as a result. More than one-fourth of the children witnessed another person being violently attacked. More than 10 percent of the children surveyed reported that they were indirectly exposed to violence.

More needs to be understood about how exposure to individual episodes of violence, repeated exposure to violence, and multiple types of exposure affect children and families, providing many avenues 


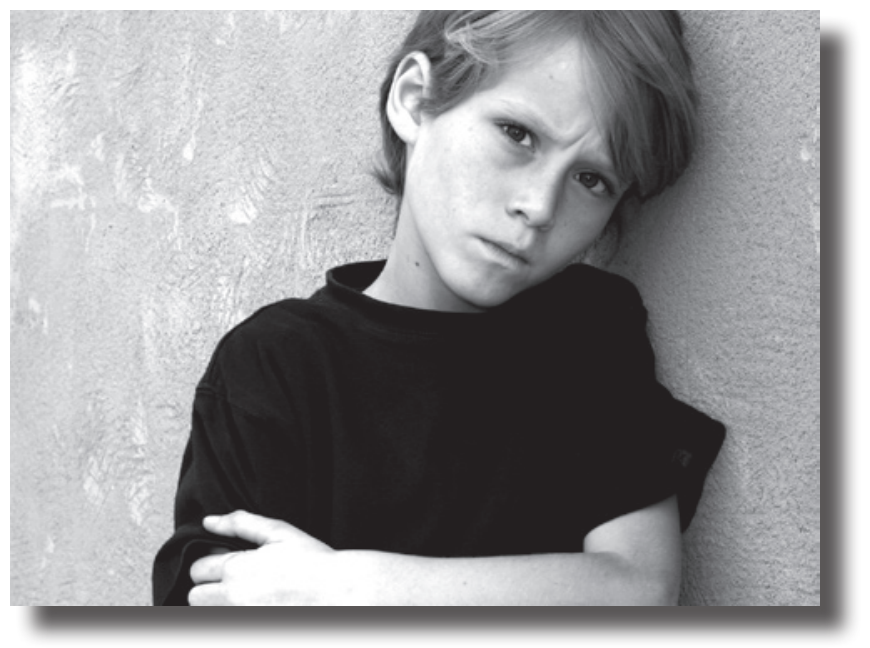

for research and policy development. As in this study, future research and policy development efforts must incorporate a broader perspective in documenting the full scope of children's exposure to violence.

\section{Understanding the Progression of Violence}

NatSCEV detailed the extent to which children in this country are exposed to serious violence. The study found that in the year prior to being interviewed, 1 in 20 children witnessed someone being shot, 1 in 200 witnessed a murder, and 1 in 50 was sexually assaulted. The survey showed that as children grow older the incidences of victimization increase. Among 14- to 17-year-old participants, 1 in 10 witnessed a shooting in the past year, 1 in 75 witnessed a murder, and 1 in 20 was sexually assaulted. NatSCEV differs from earlier studies in that it looks across the full spectrum of violence, examining and comparing the incidence of different types of violence within broad categories and determining which types are more or less frequent. The study looks not only at when and how children become more vulnerable to increasingly serious types of violence as they grow older, it also tracks the cumulative effects of exposure to violence over time. For example, although all age groups are vulnerable to simple assault, older children and adolescents are several times more likely to be sexually assaulted or to witness a shooting than are younger children.

The NatSCEV study clearly illustrates the cumulative effects on children exposed to multiple incidents of violence and how exposure to one form of violence may make a child more vulnerable to other forms. Nearly two in five children surveyed were exposed to two or more types of violence in the previous year. More than 1 in 10 was exposed to 5 or more different types of violence during that year. These children are the most likely to suffer serious long-term physical, emotional, and mental harm (Finkelhor, Ormrod, and Turner, 2007a, 2007b, 2007c). Many previous studies have shown how exposure to violence has damaging consequences for the physical and mental health of youth (Gilbert et al., 2009; Widom, 1998; Fantuzzo and Mohr, 1998; Hurt et al., 2001) and their long-term functioning and well-being as adults (Fergusson, Boden, and Horwood, 2008; Fergusson and Horwood, 1998; Kendall-Tackett, 2003).

\section{Expanding the Inquiry}

Researchers and practitioners need to ask children more specific questions about a broader range of victimizations, including dating violence, emotional abuse, and exposure to violence within the family. It is also critical to ask children who are suffering from one form of victimization about additional forms of victimizations they may have experienced to fully address their mental and emotional health needs. Practitioners also need to investigate victimization across all age ranges with the help of instruments geared to younger children and (as was done in the NatSCEV study) the use of proxies, such as parents and caretakers.

NatSCEV differs from earlier studies in that it examines and compares the incidence of different types of violence within broad categories and determines which types of violence occur more or less frequently. For example, the research team broke assaults down into peer and sibling assaults, assaults without weapon or injury, and more serious types of assaults. Peer and sibling assaults were common across all age ranges and across both genders. More serious types of assaults included assaults with a weapon, assaults with injury, gang assaults, attempted assaults, genital assaults, dating violence, and bias attacks (which were less common).

\section{Monitoring Exposure Over Time}

More research is also needed that follows children into adulthood to assess the effects of violence on their long-term health and well-being. Such research would complement those studies, such as the ACE study discussed earlier, that have taken a retrospective look at the effects of adverse childhood experiences. NatSCEV's findings affirm that more needs to be done to measure children's exposure to violence on an ongoing and systematic basis using public surveillance mechanisms, including followup surveys and long-term monitoring (Kracke and Hahn, 2008).

The estimates of specific exposures in NatSCEV are roughly equivalent to or somewhat higher than the estimates in previous community survey studies of child physical abuse (Theodore et al., 2005); sexual victimization (Theodore et al., 2005); sexual assault (Kilpatrick, Saunders, and Smith, 2003; Finkelhor, Hammer, and Sedlak, 2008); physical assault with a weapon (Kilpatrick, Saunders, and Smith, 2003); witnessing violence (Kilpatrick, Saunders, and Smith, 2003); dating violence (Wolitzky-Taylor et al., 2008); and bullying (Nansel et al., 2003). Differences in age range and definition account for some variations between the findings of this and other studies. Because this is the first national study to ask children and their caregivers directly about exposure to certain types of family violence, such as assaults by one parent on another, the exposure rate of 6.2 percent is several times greater than estimates obtained from cases disclosed to child protection agencies (Administration on Children, Youth and Families, 2004) and law enforcement (Federal Bureau of Investigation, 2007). 


\section{Reaching Across Disciplines}

This study's findings confirm that more needs to be done at all levels of policy and practice to reach across disciplines to identify children at risk from exposure to violence and to coordinate the delivery of services to these children. For example, first responders and providers who are involved in incidents of domestic violence and deal with victims in their aftermath (e.g., police, emergency room physicians and nurses, social workers, domestic violence advocates, and judges) should be aware not only of the adult victims but also of the children who may have witnessed the incident. They may also need to work with childcare providers, teachers, and school counselors and psychologists to assess the effects on a child's interaction with his or her classmates and to provide needed help.

\section{Expanding Identification Capabilities}

Researchers, practitioners, and policymakers need to collaborate to develop and expand effective screening and assessment tools that are developmentally appropriate for children across all age ranges and types of violence. These instruments and tools can identify children who are suffering emotionally, socially, physically, and developmentally. More importantly, these instruments can aid practitioners, advocates, frontline service providers, and responders across all service sectors to reach and help those children. Understanding the full extent of children's exposure to violence and the interactions among multiple types of violence more comprehensively can further practitioners' ability to respond to those families who need support and to alleviate the harmful effects of exposure to violence (Kracke and Hahn, 2008).

\section{Coordinating Across Sectors}

Finally, just as the NatSCEV study by its comprehensive nature addresses the fragmentation that, until now, characterized many attempts to look at child victimization and exposure to violence, greater coordination of the efforts to combat the effects of that victimization are needed. For example, recent initiatives have formed to separately address bullying, dating violence, and sexual harassment. At the Federal, State, tribal, and local levels, responsibility for dealing with children's exposure to violence is distributed across all service and response sectors (e.g., health departments, hospitals, child welfare and protection agencies, early childhood educators and childcare providers, schools and educational institutions, domestic violence service providers and advocates, law enforcement agencies, and the justice system). The Safe Start Initiative has worked toward a comprehensive approach across the continuum of prevention, intervention, treatment, and response for 10 years and has made significant progress in increasing knowledge, skills, and awareness of children's exposure to violence. More work is needed.

The next step in addressing children's exposure to violence and efforts to ameliorate or eliminate the harm it causes is to foster and sustain a comprehensive approach in both practice and research that builds on the groundwork established under Safe Start and this study. It is important to develop, implement, and evaluate programs and policies designed to prevent children's exposure to violence; to craft and implement strategies and interventions to help children who have been exposed to violence and their families; and to replicate those programs, policies, and interventions that prove to be effective in preventing and lessening violence against children in communities across the Nation.

The NatSCEV study represents the best attempt to date to quantify children's exposure to violence. Understanding categories and forms of violence is critical to creating appropriate interventions to prevent and suppress violence and to treat its victims. This study's greatest contribution, however, is that it highlights the degree to which children in this country live with violence in their daily lives. Violence takes a toll on children whether as victims or witnesses. Seemingly minor incidents may have long-lasting and far-reaching consequences. If policymakers, practitioners, advocates, and the general public are to respond effectively to curb the negative effects of children's exposure to violence, everyone must look at the problem in its totality and make a coordinated effort to help the children and their families who suffer these effects.

\section{For Further Information}

To learn more about the Safe Start Initiative, visit www.safestartcenter.org.

For more information about the National Survey of Children's Exposure to Violence, visit the Crimes against Children Research Center Web site at www.unh.edu/ccrc.

\section{Endnotes}

1. According to the 2005 National Crime Victimization Survey, 44 per 1,000 juveniles ages 12 to 15 and 44.2 per 1,000 adolescents and young adults ages 16 to 19 were victims of violent crime, as compared with a victimization rate of 21.2 per 1,000 for all persons age 12 and older (Baum, 2005).

2. Background material adapted from information on the Safe Start Center Web site. For more detailed information, go to www.safestartcenter.org.

3. Kracke and Hahn (2008) cite studies that estimate children's exposure to violence as ranging from 3 million to 17 million incidents. As they note, however, these studies measured only children's witnessing of domestic violence. They did not measure violence that was inflicted on children directly or violence that children witnessed outside the home.

4. For an overview of these studies, see Kracke and Hahn (2008).

5. For an overview of research on child abuse and other forms of maltreatment and their long-term health and behavioral consequences, see Repetti, Taylor, and Seeman (2002).

6. The categories of adverse childhood experiences studied were psychological, physical, or sexual abuse; violence against mother; or living with household members who were substance abusers, mentally ill or suicidal, or ever imprisoned. For more information on the ACE study, see Centers for Disease Control and Prevention (2006) and Felitti et al. (1998).

7. The aggregate figure for any sexual victimization did not include unwanted online sexual solicitation (Finkelhor et al., 2009).

8. Previous studies have also noted that low-income and minority youth are many times more likely to have witnessed serious violence in the community. Kracke and Hahn (2008) cite studies noting that only 1 percent of upper-middle-class youth had witnessed a murder and 9 percent had witnessed a stabbing (Gladstein, Rusonis, and Heald, 1992), whereas 43 percent of low-income African American school-aged children had witnessed a murder and 56 percent had witnessed a stabbing (Fitzpatrick and Boldizar, 1993). 


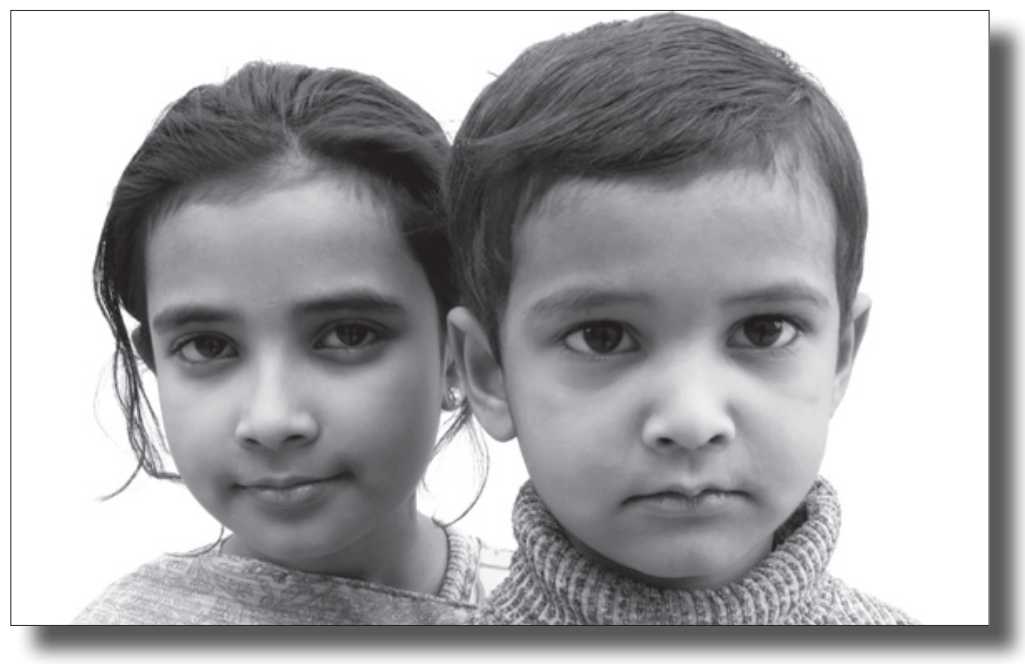

\section{References}

Administration on Children, Youth and Families. 2004. Child Maltreatment 2002: Reports From the States to the National Child Abuse and Neglect Data System. Washington, DC: U.S. Department of Health and Human Services, Administration on Children, Youth and Families.

Baum, K. 2005. Juvenile Victimization and Offending, 1993-2003. Washington, DC: U.S. Department of Justice, Office of Justice Programs, Bureau of Justice Statistics.

Centers for Disease Control and Prevention. 2006. Adverse Childhood Experiences Study: Major Findings. Atlanta, GA: U.S. Department of Health and Human Services, Centers for Disease Control and Prevention. Available from www.cdc.gov/ nccdphp/ace/findings.htm.

Fantuzzo, J., and Mohr, W. 1999. Prevalence and effects of child exposure to domestic violence. The Future of Children 9(3):21-32.

Federal Bureau of Investigation. 2007. Crime in the United States, 2006. Available from www.fbi.gov/ucr/cius/2006/. Retrieved from the Internet on February 11, 2009.

Felitti, V.J., Anda, R.F., Nordenberg, D., Williamson, D.F., Spitz, A.M., and Edwards, V. 1998. Relationship of childhood abuse and household dysfunction to many of the leading causes of death in adults: The Adverse Childhood Experiences (ACE) Study. American Journal of Preventive Medicine 14(4):245-258.
Fergusson, D.M., Boden, J.M., and Horwood, L.J. 2008. Exposure to childhood sexual and physical abuse and adjustment in early adulthood. Child Abuse \& Neglect 32:607-619.

Fergusson, D.M., and Horwood, L.J. 1998. Exposure to interparental violence in childhood and psychosocial adjustment in young adulthood. Child Abuse \& Neglect 22(5):339-357.

Finkelhor, D. 2008. Childhood Victimization: Violence, Crime, and Abuse in the Lives of Young People. New York, NY: Oxford University Press.

Finkelhor, D., Hammer, H., and Sedlak, A. 2008. Sexually Assaulted Children: National Estimates and Characteristics. Washington, DC: U.S. Department of Justice, Office of Justice Programs, Office of Juvenile Justice and Delinquency Prevention.

Finkelhor, D., Ormrod, R.K., and Turner, H.A. 2007a. Poly-victimization: A neglected component in child victimization trauma. Child Abuse \& Neglect 31:7-26.

Finkelhor, D., Ormrod, R.K., and Turner, H.A. 2007b. Poly-victimization and trauma in a national longitudinal cohort. Development and Psychopathology 19(1):149-166.

Finkelhor, D., Ormrod, R.K., and Turner, H.A. 2007c. Revictimization patterns in a national longitudinal sample of children and youth. Child Abuse \& Neglect 31(5):479-502.

Finkelhor, D., Ormrod, R.K., Turner, H.A., and Hamby, S.L. 2005. The victimization of children and youth: A comprehensive, national survey. Child Maltreatment 10(1):5-25.
Finkelhor, D., Turner, H.A., Ormrod, R.K., and Hamby, S.L. 2009. Violence, crime, and exposure in a national sample of children and youth. Pediatrics 124(5) (November).

Fitzpatrick, K.M., and Boldizar, J.P. 1993. The prevalence and consequences of exposure to violence among AfricanAmerican youth. Journal of the American Academy of Child and Adolescent Psychiatry 32:424-430.

Gilbert, R., Widom, C.S., Browne, K.D., Fergusson, D.M., Webb, E., and Janson, S. 2009. Burden and consequences of child maltreatment in high-income countries. The Lancet 373(9657):68-81.

Gladstein, J., Rusonis, E.J., and Heald, F.P. 1992. A comparison of inner-city and upper-middle-class youth's exposure to violence. Journal of Adolescent Health $13: 275-280$.

Hashima, P., and Finkelhor, D. 1999. Violent victimization of youth versus adults in the National Crime Victimization Survey. Journal of Interpersonal Violence 14(8):799-820.

Hurt, H., Malmud, E., Brodsky, N.L., and Giannetta, J. 2001. Exposure to violence: Psychological and academic correlates in child witnesses. Archives of Pediatrics \& Adolescent Medicine 155(12):1351-1356.

Kendall-Tackett, K. 2003. Treating the Lifetime Health Effects of Childhood Victimization. Kingston, NJ: Civic Research Institute.

Kilpatrick, D.G., Saunders, B.E., and Smith, D.W. 2003. Youth Victimization: Prevalence and Implications. Washington, DC: U.S. Department of Justice, Office of Justice Programs, National Institute of Justice.

Kracke, K., and Hahn, H. 2008. The nature and extent of childhood exposure to violence: What we know, why we don't know more, and why it matters. Journal of Emotional Abuse 8(1/2):29-49.

Nansel, T.R., Overpeck, M.D., Haynie, D.L., Ruan, W.J., and Scheidt, P.C. 2003. Relationships between bullying and violence among US youth. Archives of Pediatrics \& Adolescent Medicine 157(4):348-353.

Rand, M.R. 2008. Criminal Victimization, 2007. Washington, DC: U.S. Department of Justice, Office of Justice Programs, Bureau of Justice Statistics. 
Repetti, R.L., Taylor, S.E., and Seeman T.E. 2002. Risky families: Family social environments and the mental and physical health of offspring. Psychology Bulletin 128(2):330-366.

Theodore, A.D., Chang, J.J., Runyan, D.K., Hunter, W.M., Bangdiwala, S.I., and Agans, R. 2005. Epidemiologic features of the physical and sexual maltreatment of children in the Carolinas. Pediatrics 115(3):331-337.

Widom, C.S. 1998. Childhood victimization: Early adversity and subsequent psychopathology. In Adversity, Stress, and Psychopathology, edited by B.P. Dohrenwend. New York, NY: Oxford University Press.
Wolitzky-Taylor, K.B., Ruggiero, K.J., Danielson, C.K., Resnick, H.S., Hanson, R.F., Smith, D.W., Saunders, B.E., and Kilpatrick, D.G. 2008. Prevalence and correlates of dating violence in a national sample of adolescents. Journal of the American Academy of Child and Adolescent Psychiatry 47(7):755-762.

This Bulletin was prepared under cooperative agreement number 2005-JL-FX-0048 from the Office of Juvenile Justice and Delinquency Prevention (OJJDP), U.S. Department of Justice.

Points of view or opinions expressed in this document are those of the authors and do not necessarily represent the official position or policies of OJJDP or the U.S. Department of Justice.

\section{Acknowledgments}

This Bulletin was written by David Finkelhor, Ph.D., Director, Crimes against Children Research Center, University of New Hampshire; Heather Turner, Ph.D., Professor, Crimes against Children Research Center, University of New Hampshire; Richard Ormrod, Ph.D., Research Professor, Crimes against Children Research Center, University of New Hampshire; Sherry Hamby, Ph.D., Research Associate Professor, Department of Psychology, Sewanee, University of the South; and Kristen Kracke, M.S.W., Safe Start Initiative Coordinator and Program Manager, Office of Juvenile Justice and Delinquency Prevention (OJJDP). OJJDP wishes to acknowledge the contributions to this Bulletin of James A. Mercy, Ph.D., Special Adviser for Strategic Directions, Division of Violence Prevention, National Center for Injury Prevention and Control, Centers for Disease Control and Prevention; and Rebecca T. Leeb, Ph.D., Epidemiologist, Division of Violence Prevention, National Center for Injury Prevention and Control, Centers for Disease Control and Prevention. OJJDP also wishes to acknowledge the support of CDC for the National Survey of Children's Exposure to Violence and its partnership in the Safe Start Initiative to create safe, stable, and nurturing environments for children and their families. The authors wish to thank Brian Higgins, Writer/Editor, Lockheed Martin's Office of Justice Programs Communication and Publication Support Services, for his assistance in editing and coordinating the production of this Bulletin.

\section{Share With Your Colleagues}

Unless otherwise noted, OJJDP publications are not copyright protected. We encourage you to reproduce this document, share it with your colleagues, and reprint it in your newsletter or journal. However, if you reprint, please cite OJJDP and the authors of this Bulletin. We are also interested in your feedback, such as how you received a copy, how you intend to use the information, and how OJJDP materials meet your individual or agency needs. Please direct your comments and questions to:

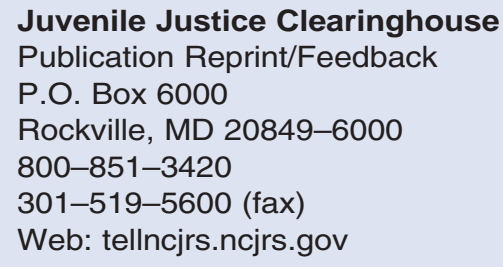

The Office of Juvenile Justice and Delinquency Prevention is a component of the Office of Justice Programs, which also includes the Bureau of Justice Assistance; the Bureau of Justice Statistics; the Community Capacity Development Office; the National Institute of Justice; the Office for Victims of Crime; and the Office of Sex Offender Sentencing, Monitoring, Apprehending, Registering, and Tracking (SMART). 
U.S. Department of Justice

PRESORTED STANDARD

Office of Justice Programs

Office of Juvenile Justice and Delinquency Prevention

Washington, DC 20531

Official Business

Penalty for Private Use $\$ 300$ 